\title{
Interpretação de pronomes em português L2: efeitos de transferência?*
}

\author{
Alexandra Fiéis \& Ana Madeira \\ CLUNL/NOVA FCSH
}

\begin{abstract}
:
This study investigates how knowledge of the interpretative properties of strong object pronouns develops in L2 European Portuguese. We focus on the anaphor si, which, in biclausal domains, may take either a local or a long-distance antecedent. Previous studies have shown that L2 learners show delays in the acquisition of non-reflexive pronouns in monoclausal domains (Kim et al 2014), but not of anaphors; however, knowledge of the locality constraints on anaphors in biclausal sentences has been shown to exhibit transfer effects and develop late (Domínguez et al 2012). In this study we investigate whether the learners' L1 influences the development of the interpretative properties of pronouns by considering two groups of learners whose L1s differ regarding long-distance binding: Spanish, where it is disallowed (Otero 1999), and Italian, where, according to Napoli (1979), it is allowed. Moreover, we investigate whether learners attain full knowledge of these properties, and, if so, whether development of this knowledge is delayed, by comparing learners at different proficiency levels (intermediate and advanced). Results of two truth-value judgement tasks indicate the presence of L1 effects in learners' interpretation of non-reflexive pronouns, but not of si in biclausal contexts, where a local interpretation is preferred over a long-distance one. Moreover, a comparison between the intermediate and the advanced groups reveals a developmental effect in the Spanish group (but not in the Italian group), indicating that the interpretative properties of si may be fully acquired, albeit subject to delays.
\end{abstract}

Keywords: referential dependency, long distance binding, L2 European Portuguese, L1 influence

Palavras-chave: dependência referencial, ligação de longa distância, português europeu L2, influência da L1

\section{Introdução}

Neste trabalho, investigamos a aquisição das propriedades interpretativas de pronomes em frases simples e complexas em português europeu (PE) L2, procurando perceber se se verificam efeitos de transferência neste domínio.

Estudos anteriores mostram que, em geral, os aprendentes de L2 adquirem plenamente as condições que regulam a interpretação de pronomes fortes reflexos e não reflexos, embora o conhecimento destas condições estabilize mais tarde no caso dos não reflexos (e.g. Kim, Montrul \& Yoon, 2014). Estes atrasos poderão dever-se a problemas na integração do conhecimento sintático e discursivo-pragmático necessário à sua interpretação (e.g. Kim et al., 2014). Quanto aos reflexos, alguns estudos (e.g. Domínguez, Hicks \& Song, 2012) reportam efeitos de transferência da L1 em contextos potenciais de ligação de longa distância, enquanto outros estudos não observam influência da L1 neste domínio (e.g. Thomas, 1989; White et al., 1997).

No presente estudo, investigamos a aquisição, em frases simples e complexas, das propriedades interpretativas do pronome reflexo si, que permite antecedentes locais e não locais em PE (Brito, 2003;

\footnotetext{
* Este trabalho foi financiado pela FCT, através do Projeto Estratégico do Centro de Linguística da Universidade Nova de Lisboa UID/LIN/03213/2013. Agradecemos a todos os informantes que participaram no estudo, bem como aos professores do Curso de Língua e Cultura Portuguesa, da Faculdade de Ciências Sociais e Humanas da Universidade Nova de Lisboa, pela colaboração prestada na recolha de dados. Agradecemos ainda à Cláudia Martins pela recolha dos dados.
} 
Menuzzi \& Lobo, 2016), e do pronome não reflexo de $3 .^{a}$ pessoa (apenas em frases simples), procurando compreender se se verificam efeitos de L1 e efeitos de desenvolvimento na interpretação destes pronomes. $\mathrm{O}$ estudo baseia-se em duas tarefas de juízos de valor de verdade e investiga participantes de nível intermédio e avançado, falantes nativos de italiano, uma língua que, à semelhança do português, tem um pronome reflexo que, de acordo com Napoli (1979) e Giorgi (1984), também permite ligação por antecedentes não locais, e espanhol, que não permite ligação de longa distância (Otero, 1999). Assumimos que a transferência da L1 desempenha um papel na aquisição de L2 (e.g. Schwartz \& Sprouse, 1996) e prevemos diferenças no desempenho de aprendentes cujas L1s apresentam propriedades distintas na interpretação de pronomes. Além disso, assumindo que o conhecimento de propriedades sintáticas pode desenvolver-se plenamente ao longo do processo de aquisição de L2 (White, 2003), predizemos que propriedades sujeitas a variação paramétrica, como é o caso da ligação de longa distância (e.g. Manzini \& Wexler, 1987), podem ser plenamente adquiridas (embora possam estar sujeitas a atrasos), enquanto propriedades de interface, como a interpretação de pronomes não reflexos, se desenvolverão mais tardiamente, podendo nunca ser plenamente adquiridas (Sorace, 2011).

O artigo está organizado da seguinte forma: na secção 2, descrevemos as propriedades do pronome reflexo si em PE; na secção 3, revemos alguns estudos anteriores sobre a aquisição de L2 de dependências referenciais que envolvem pronomes reflexos e não reflexos; na secção 4, apresentamos as questões de investigação; na secção 5, descrevemos a metodologia - as duas tarefas experimentais, os procedimentos, os participantes e as hipóteses; na secção 6, descrevemos os resultados das duas tarefas de juízos de valor de verdade; e, finalmente, na secção 7, discutimos os resultados, apresentamos as conclusões, e identificamos algumas questões para trabalho futuro.

\section{A anáfora si em PE}

Em PE, o pronome reflexo si, que ocorre em contextos preposicionais, comporta-se quer como uma anáfora local quer como uma anáfora de longa distância. Assim, em (1a), si é um reflexo ligado localmente pelo sujeito a Maria, mas, em (1b), pode retomar tanto o sujeito da oração subordinada o João como o sujeito da matriz a Maria (em ambas as frases pode ainda ser interpretado como um pronome formal de $2 .^{\mathrm{a}}$ pessoa do singular):

(1) a. A Maria falou mal de $\mathrm{si}_{\mathrm{i} / \mathrm{j}}$

b. A Maria $a_{i}$ disse que o João falou mal de $\mathrm{si}_{\mathrm{i} / \mathrm{j} / \mathrm{k}}$

Note-se que, nas gramáticas de falantes nativos adultos de PE, em frases como (1a), o pronome reflexo si pode alternar com um pronome não reflexo de $3 .^{\mathrm{a}}$ pessoa, uma vez que, nestes contextos, os pronomes não reflexos podem também retomar um antecedente local, como se mostra em (2) (Menuzzi, 1999). Silva (2015), por exemplo, observou que o grupo de controlo do seu estudo, constituído por 40 adultos falantes nativos de PE, apresentou uma taxa de aceitação desta leitura de $20 \%$.

(2) A Maria falou mal dela $\mathrm{j}_{\mathrm{j}} / \operatorname{dela}_{\mathrm{i}}\left(=\mathrm{de} \mathrm{si}_{\mathrm{i}}\right)$

Nestes casos, a interpretação do pronome depende das propriedades lexicais do predicado, em particular, do grau de reflexividade inerente do predicado (Reinhart \& Reuland 1993). Assim, esta interpretação de ligação a um antecedente local é menos aceitável com predicados com os quais uma interpretação correferencial é menos natural devido às suas propriedades semânticas e pragmáticas, como é o caso do verbo lutar em (3): 
(3) Maria $\mathrm{i}_{\mathrm{i}}$ luta contra ela $\mathrm{j} /$ ??ela $\mathrm{a}_{\mathrm{i}}\left(=\mathrm{si}_{\mathrm{i}}\right)$, mas o vício é forte

(Menuzzi \& Lobo 2016:344)

Assim, a interpretação reflexiva de pronomes não reflexos em contextos preposicionais como os ilustrados em (2) e (3) depende tanto de condições lexicais como de condições semânticas e pragmáticas.

Observámos que, em frases complexas como (1b) acima, a interpretação da anáfora si é potencialmente ambígua, pois pode retomar quer um antecedente local quer um antecedente não local. A ambiguidade que surge nestes contextos pode ser cancelada pela inserção da expressão anaforizante mesma $(o)$ ou própria $(o)$ :

(4) a. A Maria disse que o João ${ }_{j}$ falou mal de si mesma

b. A Maria $a_{i}$ disse que o João falou mal de si mesmo

A ocorrência de anáforas de longa distância está sujeita a variação paramétrica, que tem sido atribuída quer a propriedades de itens lexicais específicos (Manzini \& Wexler 1987) quer a diferenças nas configurações de traços formais (Chomsky 2000; Domínguez et al. 2012). Nas línguas em que ocorrem, estas anáforas tendem a apresentar algumas propriedades em comum - em geral, são formas morfologicamente simples (Pica 1987) (veja-se os exemplos do italiano em (5)) e retomam obrigatoriamente um antecedente em posição de sujeito (veja-se os exemplos do português e do italiano em (6)).

(5) a. Credo [che Mario ${ }_{i}$ sostenga [che tu abbia parlato di sé $e_{i}$ e della sua famiglia in TV]] creio que Mario afirma que tu tenhas falado de REFL e da sua família na TV

b. *Gianni $i_{i}$ pensava [che quella casa appartenesse ancora a se stesso ${ }_{i}$ ]

Gianni pensava que aquela casa pertencesse ainda a REFL

(Giorgi, 1984)

(6) a. A Maria $a_{i}$ soube diretamente do João que alguém tinha falado mal de $\mathrm{si}_{\mathrm{i} / \mathrm{j} / \mathrm{k}}$

(Brito, 2003:814)

b. *Ha sorpreso la signora ${ }_{i}$ chè io giacessi presso di sé surpreendeu a senhora que eu deitasse junto de REFL

(Napoli, 1979:10)

Contudo, as anáforas de longa distância apresentam também características que as distinguem, mesmo quando ocorrem em línguas tipologicamente próximas. Por exemplo, enquanto, em PE, si pode ocorrer com uma interpretação de longa distância em domínios infinitivos, de conjuntivo e de indicativo (cf. (7)), em italiano, de acordo com Napoli (1979), a anáfora sé está excluída de orações com indicativo (cf. (8)).

(7) a. A Maria disse para o João ${ }_{j}$ apontar para $\mathrm{si}_{\mathrm{i} / \mathrm{j}}$

[INFINITIVO]

b. A Maria disse que o João $_{\mathrm{j}}$ apontasse para $\mathrm{si}_{\mathrm{i} / \mathrm{j}} \quad$ [CONJUNTIVO]

c. A Maria $a_{i}$ disse que o João $o_{j}$ apontou para $\mathrm{si}_{\mathrm{i} / \mathrm{j}}$

[INDICATIVO]

(8) a. La signora ${ }_{i}$ mi dice di giacere presso di sé a senhora me diz de deitar junto de REFL

b. La signora dice che io giaccia presso di sé $_{i}$ a senhora me diz que eu deite junto de REFL

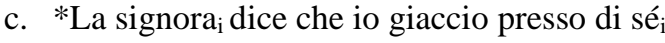
a senhora me diz que eu deito junto de REFL

[INFINITIVO]

[CONJUNTIVO]

[INDICATIVO]

(Napoli, 1979:18-19) 
Note-se, no entanto, que não existe unanimidade nos juízos dos falantes nativos de italiano quanto à possibilidade de o reflexo sé admitir uma interpretação de longa distância - Manzini \& Wexler (1987), por exemplo, consideram esta interpretação agramatical, como se indica no exemplo em (9) (retirado de Manzini \& Wexler, 1987:41).

(9) Alice $_{j}$ pensava che Marioi avesse guardato sé $_{\mathrm{i} / *_{\mathrm{j}}}$ nello specchio Alice pensava que Mario tivesse olhado REFL no espelho

O caso do espanhol, por seu turno, parece ser consensual, uma vez que o pronome reflexo sí não permite ligação de longa distância (10):

(10) $\mathrm{Juan}_{\mathrm{i}}$ insiste [en que Ana $\mathrm{j}_{\mathrm{j}}$ confía en sí *ijj] ] Juan insiste em que Ana confia em REFL

(Otero, 1999:1446)

\section{Dependências referenciais em L2}

Muitos estudos sobre o desenvolvimento de dependências referenciais em L2 têm mostrado que as condições que determinam a distribuição e interpretação de pronomes reflexos e não reflexos podem ser plenamente adquiridas. Contudo, existem algumas evidências de uma assimetria na interpretação de pronomes em contextos de ligação local, com atrasos na aquisição das propriedades dos pronomes não reflexos (e.g. Shirahata, 2007). Estes atrasos poderão dever-se a dificuldades na integração do conhecimento sintático e pragmático necessário à interpretação destes pronomes, particularmente em contextos potencialmente ambíguos como o ilustrado em (11) (Kim et al., 2014:10).

(11) Mickey $_{\mathrm{i}}$ was holding a picture of him $_{?_{\mathrm{i} j}}$

Mickey estava a segurar uma imagem de PRON

Esta assimetria na compreensão de pronomes reflexos e não reflexos é semelhante à que tem sido observada na aquisição de L1, em que se verifica que as crianças permitem uma interpretação anafórica para os pronomes não reflexos em contextos de ligação local (e.g. Chien \& Wexler, 1990; Silva, 2015). Os atrasos no desenvolvimento da interpretação dos pronomes não reflexos poderão resultar de uma diferença nos dois tipos de pronomes: enquanto os pronomes reflexos são legitimados na sintaxe (princípio A da teoria da ligação, que requer que o pronome reflexo tenha um antecedente que o c-comande no seu domínio local), a legitimação de pronomes não reflexos envolve a interface sintaxe (princípio de ligação $\mathrm{B}$, que proíbe que o pronome seja ligado por um antecedente local) / discurso-pragmática. De acordo com a proposta de Chien \& Wexler (1990), a aquisição dos princípios da ligação (sintáticos) precede a aquisição dos princípios pragmáticos que governam o estabelecimento de relações de correferência. Grodzinsky \& Reinhart (1993), por outro lado, defendem que as dificuldades se situam ao nível da performance, e não da competência, resultando de limitações de processamento.

Um contexto em que tem sido demonstrado que os falantes não nativos exibem dificuldades também na interpretação de pronomes reflexos é o contexto de frase complexa. Estas dificuldades têm sido observadas quer em falantes de línguas com ligação de longa distância que adquirem uma língua como o inglês, que apenas permite a ligação local do reflexo em frases como (12), quer em falantes de línguas como o inglês que adquirem uma língua com longa distância como o japonês, o coreano ou o chinês (veja-se os exemplos do chinês em (13)).

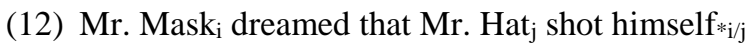
"O sr. Mask sonhou que o sr. Hat disparou contra REFL"

(Domínguez et al. 2012:22) 
(13) a. Zhangsan ${ }_{i}$ renwei Lisij xiangxin ziji $i_{i j}$

Zhangsan pensar Lisi confiar REFL

"Zhangsan pensa que Lisi confia em si"

(Yuan 1998:324)

b. Zhangsan ${ }_{\mathrm{i}}$ renwei Lisi $\mathrm{i}_{\mathrm{j}}$ zhidao Wangwuk xihuan ziji $\mathrm{i}_{\mathrm{j} j \mathrm{k}}$

Zhangsan pensar Lisi saber Wangwu gostar REFL

Zhangsan pensa que Lisi sabe que Wangwu gosta de si"

(Cole, Hermon \& Lee 2001:34)

Num estudo realizado com aprendentes coreanos de inglês L2, Domínguez et al. (2012) mostraram, baseando-se numa tarefa de verificação de imagens, que os aprendentes exibem atrasos na aquisição das restrições de localidade a que os pronomes reflexos estão sujeitos em frases complexas em inglês; observouse também um efeito significativo da proficiência, já que os aprendentes com um nível mais baixo de proficiência apresentavam taxas de preferência por um antecedente local para o pronome reflexo significativamente mais baixas do que os falantes mais avançados. Embora estudos como Domínguez et al. (2012) pareçam indiciar a presença de efeitos de influência da L1 em contextos potenciais de ligação de longa distância, não é claro qual o papel que a L1 dos aprendentes desempenha neste domínio, uma vez que outros estudos têm mostrado que (pelo menos alguns) falantes de línguas sem reflexos de longa distância (e.g. espanhol e francês) exibem taxas de aceitação de antecedentes não locais em inglês L2 semelhantes às apresentadas por falantes de línguas com reflexos de longa distância (e.g. chinês e japonês) (Thomas 1989, 1993; White et al., 1997). Não é claro, no entanto, em que medida é que as diferentes conclusões alcançadas por alguns destes estudos se devem a diferenças na natureza das tarefas experimentais: enquanto em alguns estudos (e.g. White et al., 1997) é apresentada apenas uma interpretação para cada frase, que os participantes devem aceitar ou rejeitar, noutros estudos (e.g. Domínguez et al., 2012) são apresentadas todas as interpretações possíveis, podendo os participantes aceitar mais do que uma interpretação para cada frase. Neste último caso, é mais provável que as respostas dos participantes reflitam mais as suas preferências por uma ou outra interpretação do que os seus juízos relativamente à possibilidade de cada uma das interpretações.

Por outro lado, os resultados de alguns trabalhos (e.g. Yuan, 1998; Sperlich, 2013) revelam a presença de efeitos de L1 na aquisição de ligação de longa distância em chinês L2 por falantes nativos de inglês, os quais evidenciam dificuldades na interpretação de reflexos de longa distância, apresentando uma preferência clara por antecedentes locais. $\mathrm{O}$ seu desempenho contrasta com o de falantes nativos de japonês e coreano, que apresentam um desempenho mais próximo do alvo do que os falantes nativos de inglês, o que indica que a L1 poderá ter um efeito facilitador no desenvolvimento do conhecimento de ligação de longa distância.

Em trabalho anterior (Fiéis \& Madeira, 2016), procurámos compreender se este efeito facilitador também se observa quando a L1 e a L2 são tipologicamente diferentes, como é o caso do português e do chinês. Os resultados de uma tarefa de juízos de valor de verdade, que testa a compreensão do pronome reflexo $s i$ em frases complexas, com dois potenciais antecedentes em posição de sujeito, mostra que aprendentes de nível intermédio de PE que têm o chinês como L1 apresentam uma taxa de aceitação elevada de antecedentes de longa distância (71\%) e uma aceitação mais baixa de antecedentes locais (47\%). Estes resultados confirmam as conclusões de, por exemplo, Yuan (1998) e Domínguez et al. (2012), já que parecem indicar que a L1 dos aprendentes tem um efeito positivo na sua aquisição das condições que governam a interpretação da anáfora si. Ao mesmo tempo, a preferência pela leitura de longa distância manifestada pelos participantes confirma também os resultados de estudos anteriores (e.g. Thomas, 1991), sugerindo que a existência de um antecedente alternativo nestes contextos afeta adversamente a aceitação de uma leitura de ligação local. 


\section{Questões de investigação}

Como foi referido na secção 3., sabemos que: (i) existem assimetrias na interpretação de pronomes reflexos e não reflexos em domínios locais na aquisição de L2 e na aquisição de L1; (ii) existem evidências de dificuldades na interpretação de anáforas em frases complexas na aquisição de L2 por aprendentes cujas L1 permitem ligação de longa distância; (iii) alguns estudos sugerem que a presença de ligação de longa distância na L1 poderá ter um efeito facilitador na aquisição deste fenómeno em L2.

Neste estudo, investigamos a aquisição de dependências referenciais em contexto de frase simples e complexa, procurando responder às seguintes questões:

(i) Observam-se dificuldades na interpretação do pronome reflexo ( $s i$ ) e não reflexo em contexto de frase simples na aquisição de português L2?

(ii) Observam-se dificuldades na interpretação da anáfora si em contextos potenciais de longa distância na aquisição de português L2?

(iii) Observam-se efeitos de L1 na interpretação da anáfora si em contextos potenciais de longa distância na aquisição de português L2?

(iv) Observam-se efeitos de desenvolvimento na interpretação da anáfora si em contextos potenciais de longa distância na aquisição de português L2?

\section{Metodologia}

Utilizaram-se, neste estudo, duas tarefas de juízos de valor de verdade (adaptadas de Silva 2015) que testam compreensão do pronome de $3 .^{a}$ pessoa do singular si em contexto preposicional em frases simples (com um antecedente possível para o pronome) e em frases complexas (com dois potenciais antecedentes para o pronome). Nos pontos seguintes, descrevem-se as tarefas, os procedimentos e os participantes no estudo, e apresentam-se as hipóteses em investigação.

\subsection{Tarefas}

Como referido anteriormente, as tarefas utilizadas neste estudo foram adaptadas ${ }^{1}$ para adultos a partir de Silva (2015), e testam compreensão do pronome de $3 .^{a}$ pessoa do singular si em contexto preposicional em frases simples e em frases complexas. Nas frases simples, foi testada a variável 'tipo de pronome' (reflexo e não reflexo) e, nas complexas, testou-se a variável 'posição do antecedente’ (local/longa distância).

\subsubsection{Tarefa 1}

$\mathrm{Na}$ tarefa 1, testou-se pronomes em contextos preposicionados em frases simples. Esta tarefa era composta por 56 itens (40 itens de teste e 16 distratores). Foram testadas as seguintes condições: pronome reflexo com interpretação de correferência $(n=10)$, pronome reflexo com referência disjunta $(n=10)$, pronome não reflexo com interpretação de correferência $(n=10)$ e pronome não reflexo com referência disjunta $(n=10)$. Utilizaram-se distratores com DPs plenos, 8 'verdadeiro' e 8 'falso'. Os verbos usados nesta tarefa são verbos

\footnotetext{
${ }^{1}$ Foram modificados algumas imagens e alguns itens lexicais. Em termos de procedimentos, para além de observarem uma imagem projetada e ouvirem um estímulo oral (dito pelo investigador), os participantes tinham também acesso ao estímulo por escrito, tendo de assinalar, na folha de resposta, a opção que consideravam mais adequada, em função da imagem que estavam a visualizar.
} 
de reflexividade improvável, como apontar, tocar, bater, disparar, e martelar, que favorecem a interpretação de referência disjunta com pronomes não reflexos.

Exemplificam-se a seguir os itens de teste utilizados para as condições testadas na tarefa 1: (A) resposta verdadeira para leitura de correferência com pronome reflexo; (B) resposta falsa para leitura de referência disjunta com pronome reflexo; (C) resposta verdadeira para leitura de referência disjunta com pronome não reflexo; e, finalmente, (D) resposta falsa para leitura de correferência com pronome não reflexo.

(A)

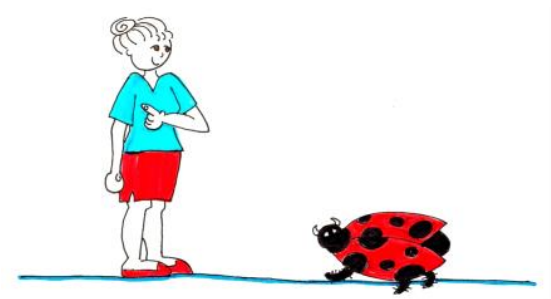

Uma avó e uma joaninha. A avó está a apontar para si?

Pronome reflexo (correferência)

Resposta esperada: verdadeiro [ $n=10]$

(C)

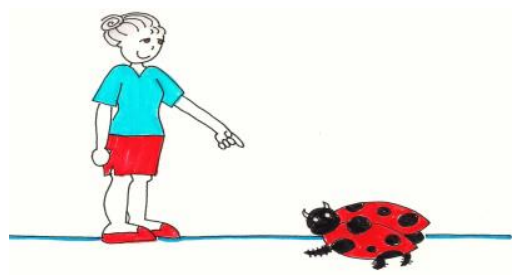

Uma avó e uma joaninha. A avó está a apontar para ela?

Pronome não reflexo (referência disjunta)

Resposta esperada: verdadeiro $[\mathrm{n}=10]$
(B)

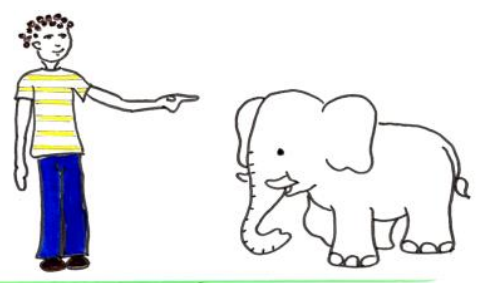

Um rapaz e um elefante. $O$ rapaz está a apontar para si?

Pronome reflexo (referência disjunta)

Resposta esperada: falso [ $\mathrm{n}=10$ ]

(D)

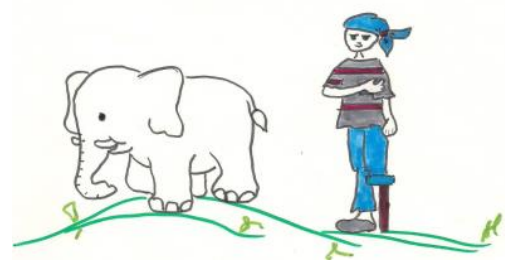

Um pirata e um elefante. $O$ pirata está a tocar nele?

Pronome não reflexo (correferência)

Resposta esperada: falso [n=10]

\subsubsection{Tarefa 2}

Na tarefa 2, testou-se compreensão do pronome reflexo si em orações complexas, tendo a posição do antecedente (local/não local) sido a variável testada. Foram utilizados 32 itens, dos quais 20 eram distratores com DPs plenos. Nesta tarefa, as condições testadas foram as seguintes: pronome reflexo com antecedente local $(n=6)$ e pronome reflexo com antecedente não local $(n=6)$.

Em (E) e (F), exemplificam-se os itens de teste utilizados para testar as condições de localidade com o reflexo si em contexto de frase complexa: (E) resposta verdadeira com pronome reflexo com antecedente local; e (F) resposta verdadeira com pronome reflexo com antecedente não local. 
(E)

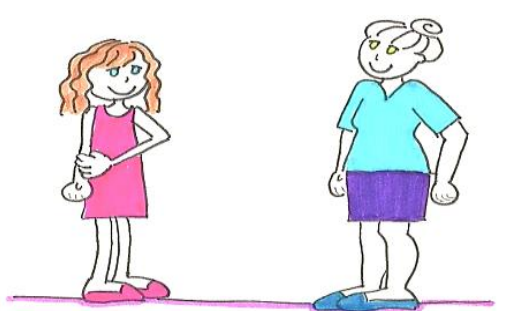

A avó acha que a rapariga está a tocar em si?

Pronome reflexo com antecedente local Resposta esperada: verdadeiro [ $\mathrm{n}=6]$
(F)

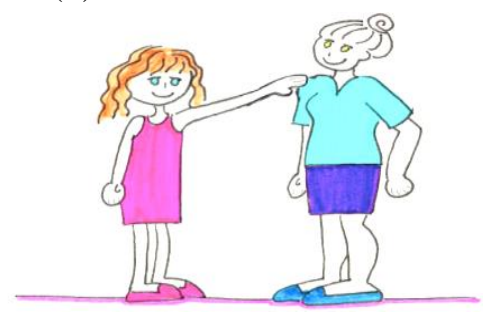

A avó acha que a rapariga está a tocar em si?

Pronome reflexo com antecedente não local Resposta esperada: verdadeiro [ $\mathrm{n}=6]$

\subsection{Procedimentos}

As tarefas foram realizadas em grupo, numa única sessão, sem tempo limite de realização. Os participantes observavam uma imagem projetada e ouviam um estímulo oral (dito pelo investigador), que era também apresentado por escrito na folha de resposta, seguido de um retângulo branco. Pedia-se aos participantes que preenchessem os retângulos brancos com SIM (S) ou NÃO (N), conforme o que consideravam mais adequado em função da imagem que estavam a visualizar. Os itens eram apresentados de forma aleatória.

\subsection{Participantes}

Os participantes são 60 aprendentes de português, de nível intermédio e avançado, falantes nativos de italiano e espanhol. Como foi referido na secção 2, de acordo com Napoli (1979) e Giorgi (1984), o italiano possui, à semelhança do português, um pronome reflexo sé que também permite ligação por antecedentes não locais, ainda que apresente propriedades diferentes das do reflexo si do português (cf. secção 2).

Todos os participantes são estudantes universitários, que se encontravam a frequentar um programa de estudos em Portugal de 1 semestre a 1 ano. Todos frequentavam aulas de português, tendo sido posicionados no início do curso num nível de proficiência intermédio (B1) ou avançado (B2/C1), e todos tinham começado a aprender português formalmente no país de origem. O estudo incluiu ainda um grupo de 43 controlos, falantes nativos de PE.

Todos os participantes falantes de italiano e espanhol L1 têm também o inglês como L2. As características dos participantes são apresentadas na tabela 1 .

\begin{tabular}{|ll|c|c|c|}
\hline & Idades & $\begin{array}{c}\text { Idade de início } \\
\text { de exposição }\end{array}$ & $\begin{array}{c}\text { Tempo de } \\
\text { exposição (em } \\
\text { anos) }\end{array}$ \\
\hline Espanhol L1 & $\mathrm{B} 1(\mathrm{n}=16)$ & $21-36(25.1)$ & $20-36(24.1)$ & $1-4(1.3)$ \\
\hline & $\mathrm{B} 2 / \mathrm{C} 1(\mathrm{n}=24)$ & $21-51(26.2)$ & $14-40(24.3)$ & $1-10(2.1)$ \\
\hline Italiano L1 & $\mathrm{B} 1(\mathrm{n}=12)$ & $20-53(25.5)$ & $19-52(24.8)$ & $0.5-2(1.2)$ \\
\hline & $\mathrm{B} 2 / \mathrm{C} 1(\mathrm{n}=8)$ & $20-29(19.3)$ & $18-25(19.8)$ & $1-4(2.3)$ \\
\hline Controlos & $(\mathrm{n}=43)$ & $18-60(24.8)$ & n.a. & n.a. \\
\hline
\end{tabular}

Tabela 1. Participantes no estudo 


\subsection{Hipóteses}

Com base nas conclusões de estudos anteriores sobre a aquisição de dependências referenciais em L2 descritas no ponto 3 , e tendo em conta as questões de investigação, foram colocadas as seguintes quatro hipóteses de investigação:

(1) Assumindo que, para falantes não nativos, as propriedades que envolvem diferentes domínios (i.e. propriedades de interface) são mais problemáticas do que as propriedades estritamente sintáticas (e.g. Sorace \& Filiaci, 2006; Sorace, 2011), espera-se que o conhecimento das condições que regulam a interpretação de pronomes se desenvolva mais tardiamente para o não reflexo do que para o reflexo (si) em ambos os grupos de L2. Predizemos, por isso, aceitação mais elevada de leitura de correferência com o sujeito com o reflexo do que de leitura de referência disjunta com o não reflexo.

(2) Embora a interpretação da anáfora si seja determinada por condições sintáticas quer em frases simples quer em frases complexas (esperando-se, pois, que sejam adquiridas pelos dois grupos de L2), a sua interpretação em frases complexas deve estar associada a custos de processamento mais elevados, uma vez que envolve uma escolha entre dois antecedentes possíveis. Predizemos, pois, melhor desempenho na interpretação de si em contexto de frase simples do que em contexto de frase complexa.

(3) Assumindo transferência da L1 na aquisição de L2 (e.g. Schwartz \& Sprouse, 1996; White, 2003), espera-se diferenças no desempenho de aprendentes cujas L1s apresentam propriedades distintas na interpretação de pronomes. Esperamos, por isso, melhor desempenho do grupo de italiano L1 do que do grupo de espanhol L1 no que se refere à interpretação da anáfora si em contextos de ligação de longa distância.

(4) Assumindo que o conhecimento de propriedades estritamente sintáticas pode desenvolver-se plenamente ao longo do processo de aquisição de L2 (e.g. Schwartz \& Sprouse, 1996; White, 2003), mesmo que, no caso de algumas propriedades mais marcadas, esse desenvolvimento possa estar sujeito a atrasos, predizemos que se observará um efeito de desenvolvimento na aquisição de ligação de longa distância, traduzindo-se num melhor desempenho dos grupos de nível avançado do que dos grupos de nível intermédio no que se refere à aceitação de antecedentes não locais para a anáfora $s i$ em contextos de ligação de longa distância.

\section{Resultados}

Nesta secção, descrevemos os resultados das duas tarefas de juízos de valor de verdade: os resultados da tarefa 1, que testa a compreensão do pronome reflexo e não reflexo em contextos preposicionados em frase simples, são descritos em 6.1., e os resultados da tarefa 2., que testa a compreensão do pronome reflexo $s i$ em frases complexas, são descritos em 6.2 .

\subsection{Interpretação dos pronomes em frases simples}

No gráfico da figura 1, apresenta-se os resultados globais da tarefa 1, que testa a interpretação do pronome reflexo e não reflexo de 3. ${ }^{a}$ pessoa em frases simples. Os valores apresentados correspondem às respostas esperadas para a interpretação de cada tipo de pronome, de acordo com os princípios A e B da Teoria da Ligação: correferência com o sujeito para o pronome reflexo, e referência disjunta com o sujeito 
para o não reflexo. No cálculo das percentagens foram incluídas respostas que correspondem quer a uma aceitação da opção esperada quer a uma rejeição da opção alternativa.

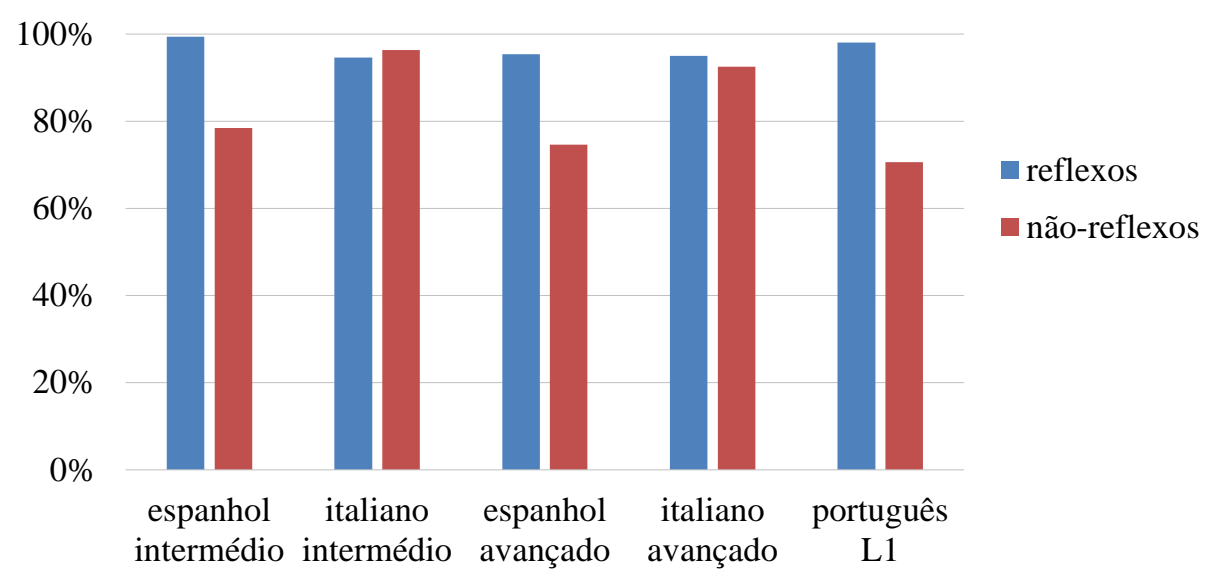

Figura 1. Resultados globais da tarefa 1 - resposta esperada na compreensão de pronomes em frases simples (correferência com o sujeito (reflexo) vs. referência disjunta (não reflexo))

Não se observam diferenças na interpretação do pronome reflexo entre os controlos e os falantes não nativos, apresentando todos os grupos uma preferência clara pela leitura de correferência (entre 95\% e 99\%). Já na interpretação do pronome não reflexo, observam-se diferenças entre os nativos de espanhol e os controlos, por um lado, e os nativos de italiano, por outro: embora os três grupos apresentem taxas elevadas de aceitação de leitura de referência disjunta relativamente ao sujeito, esta aceitação é menos marcada no grupo de espanhol L1 e no grupo de controlo (entre 71\% e 78\%) do que no grupo de italiano L1 (entre 93\% e 96\%). Não se observam diferenças, dentro de cada grupo de L1, entre os falantes de nível intermédio e os de nível avançado.

\subsection{Interpretação dos pronomes em frases complexas}

Os resultados da tarefa 2, que testa a compreensão do pronome reflexo si em frases complexas, são apresentados na figura 2 .

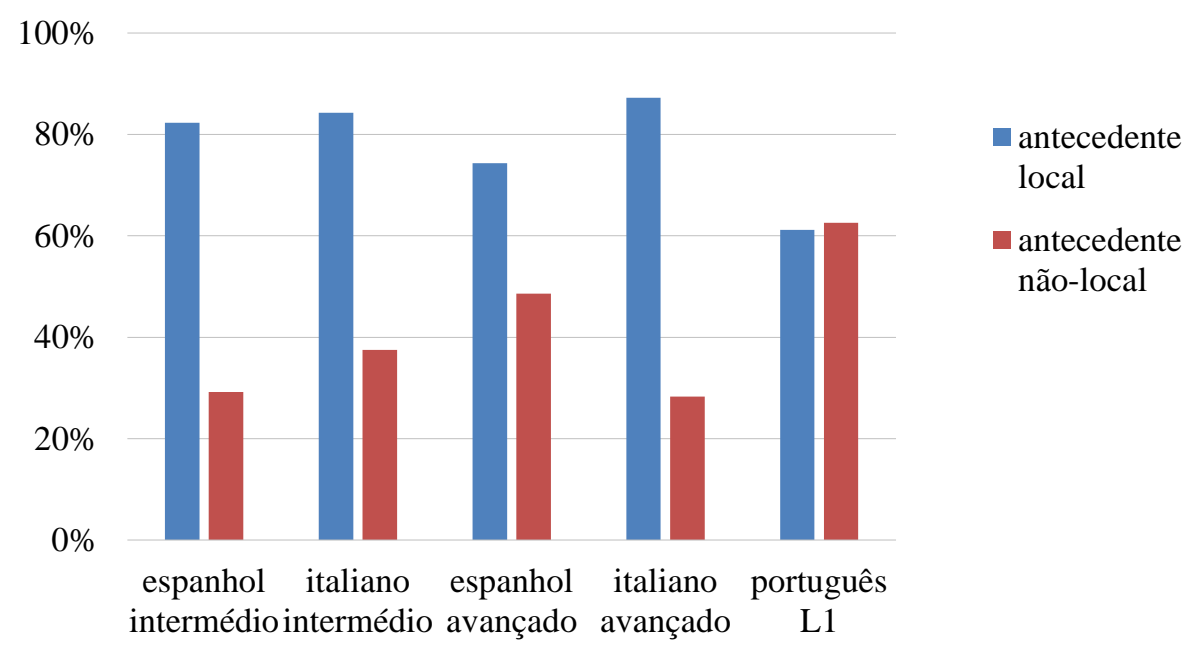

Figura 2. Resultados globais da tarefa 2 - interpretação de ligação local e de longa distância do 
Ao contrário do que se observou em frases simples, todos os grupos de não nativos exibem um comportamento claramente diferente do do grupo de controlo: apresentam taxas de aceitação mais elevadas de antecedentes locais (entre $74 \%$ e $87 \%$ vs. $61 \%$ do grupo de controlo), embora estas taxas sejam mais baixas do que as que estes grupos apresentam em contexto de frase simples; e apresentam taxas mais baixas de aceitação de antecedentes não locais (entre $28 \%$ e $49 \%$ vs. $63 \%$ do grupo de controlo). Além disso, ao contrário do grupo de controlo, que não mostra uma preferência por nenhuma das duas leituras, os grupos de não nativos preferem claramente a leitura de ligação local para o pronome.

Da análise do gráfico da figura 2, destaca-se ainda o aumento de aceitação de antecedentes não locais para o pronome si no grupo de espanhol L1, o que parece indiciar um efeito de desenvolvimento: observa-se que o desempenho do grupo intermédio difere significativamente do do grupo de controlo $((t) 57)=3.685$, $p=0.001)^{2}$, mas não se observam diferenças significativas entre o grupo de espanhol avançado e os controlos $((t(65)=1.765, p=0.082)$. Este efeito de proficiência não se observa, no entanto, no grupo de italiano L1 (na verdade, o grupo avançado até regista uma taxa de aceitação de antecedentes não locais mais baixa do que o grupo intermédio). Os dados revelam uma diferença significativa entre o desempenho dos dois grupos de italiano L1 e o dos nativos (intermédio: $((t(53)=2.523, p=0.015)$; avançados $((t(49)=3.145, p=0.003)$. De referir que o próprio grupo de controlo apresenta taxas de aceitação de antecedente não local mais baixas do que o esperado nestes contextos.

$\mathrm{Na}$ aceitação de antecedentes locais para si, podemos, novamente, observar um efeito de proficiência no grupo de espanhol L1, que se traduz na diminuição da aceitação de antecedente local para o pronome. Assim, observam-se diferenças significativas entre, por um lado, o grupo de controlo e o grupo de espanhol intermédio $((t(57)=-2.920, p=0.005)$ - mas não, note-se, entre o grupo de controlo e o grupo de espanhol avançado,$- \mathrm{e}$, por outro lado, entre os controlos e os grupos de italiano intermédio $((t(53)=-2.464, p=0.017) \mathrm{e}$ avançado $((t(49)=-2.346, p=0.023)$.

\section{Discussão e conclusões}

Os resultados descritos acima revelam a existência de uma assimetria, em frases simples, na interpretação do pronome reflexo si e do pronome não reflexo: observámos que, ao contrário do que acontece com a interpretação do pronome reflexo, em que ambos os grupos de falantes não nativos apresentam taxas de aceitação da leitura alvo (de correferência com o sujeito) idênticas às dos controlos nativos, se verificam diferenças entre os grupos na interpretação do pronome não reflexo. O contraste ocorre entre o grupo de falantes de italiano L1, que apresentam taxas de aceitação de leitura de referência disjunta (relativamente ao sujeito) mais elevadas, e os grupos de falantes de espanhol L1 e de controlo, que apresentam taxas de aceitação de referência disjunta mais baixas. Note-se, no entanto, que a interpretação de referência disjunta é a interpretação preferencial em todos os grupos, mesmo nos grupos não nativos com nível de proficiência intermédio. Assim, para os falantes não nativos, a interpretação do pronome não reflexo, que é determinada por condições na interface entre a sintaxe e o discurso-pragmática, não é necessariamente mais problemática nem se desenvolve mais tardiamente do que a interpretação do pronome reflexo, que é determinado por condições estritamente sintáticas, ao contrário do que prediz a nossa hipótese (1).

Sugerimos que as diferenças observadas no desempenho dos dois grupos não nativos poderão dever-se a influência das suas L1s. Os resultados de um breve teste de juízos de aceitabilidade que aplicámos a falantes nativos de espanhol $(n=4)$ e de italiano $(n=4)$ sugerem que existem diferenças entre as duas línguas no que diz respeito à interpretação de pronomes não reflexos em contextos preposicionais. Assim, enquanto em espanhol

\footnotetext{
${ }^{2}$ As análises estatísticas foram realizadas por meio de testes $t$ para amostras independentes (comparações intergrupos). Neste estudo, uma diferença é considerada significativa quando $p<0.05$.
} 
(à semelhança do que acontece em PE, de acordo com os juízos dos controlos nativos do nosso estudo) o pronome parece admitir uma interpretação reflexiva, particularmente quando ocorre com predicados de reflexividade provável como pensar e hablar 'falar', em italiano o pronome parece ser menos permissivo quanto à escolha de antecedentes, admitindo menos facilmente um antecedente no seu domínio local, mesmo quando ocorre com predicados de reflexividade provável. Observem-se os contrastes entre as frases do espanhol em (14) e as do italiano em (15):

(14) a. ?La abuela está apuntando hacia ella (ella = la abuela) a avó está apontando para PRON

b. *El pirata luchó contra él (él = el pirata)

o pirata lutou contra PRON

c. María solo piensa en ella (ella = María)

Maria só pensa em PRON

d. Teresa solo habla de ella (ella $=$ Teresa) Teresa só fala de PRON

(15) a. *ll nonno sta puntando verso di lui (lui = il nonno) o avô está apontando para PRON

b. *Il pirata ha combattuto contro di lui (lui = il pirata) o pirata lutou contra PRON

c. \%La nonna pensa solo a lei (lei = la nonna) a avó pensa só em PRON

d. \%Anna sta solo parlando di lei (lei = Anna) Anna está só falando de PRON

Em frases complexas, todos os grupos manifestam uma preferência por antecedentes locais, embora permitam também antecedentes de longa distância para o reflexo si. Este desempenho contrasta com o do grupo de controlo, que não apresenta uma preferência clara por qualquer uma das interpretações. À exceção do grupo de espanhol avançado, os resultados dos grupos de não nativos diferem significativamente dos resultados dos controlos nativos. Existem, pois, diferenças entre os grupos de falantes nativos de italiano e de espanhol, o que parece confirmar a nossa hipótese (3), segundo a qual deveria observar-se, entre os falantes não nativos, diferenças que são determinadas por propriedades distintas das suas L1s. No entanto, as diferenças observadas vão no sentido oposto ao esperado, uma vez que se predizia, na interpretação da anáfora si em contextos de ligação de longa distância, um melhor desempenho do grupo de italiano L1 (assumindo que o italiano, à semelhança do português, tem ligação de longa distância) do que do grupo de falantes nativos de espanhol (que não tem). Estes resultados parecem, assim, indicar que não ocorrem efeitos de L1 no desempenho destes dois grupos e que as diferenças observadas entre eles deverão ter uma outra explicação, que procuraremos explorar em trabalho futuro.

No entanto, a comparação entre os resultados dos grupos de nível intermédio do presente estudo e os do grupo de aprendentes de PE L2 nativos de chinês L1, também de nível intermédio (ver secção 3 acima), de Fiéis \& Madeira (2016) (em que foi usada a mesma tarefa de juízos de valor de verdade) revela claramente a existência de diferenças entre os grupos que apontam para a presença de efeitos de influência da L1. Como se pode verificar no gráfico da figura 3, o grupo de aprendentes chineses, cuja L1 permite ligação de longa distância, apresenta taxas mais elevadas de aceitação de ligação de longa distância com o reflexo si do que as observadas nos grupos de italiano L1 e espanhol L1. Também em contraste com estes dois grupos, esta é claramente a interpretação preferencial da anáfora si em frases complexas para o grupo de chinês L1. 


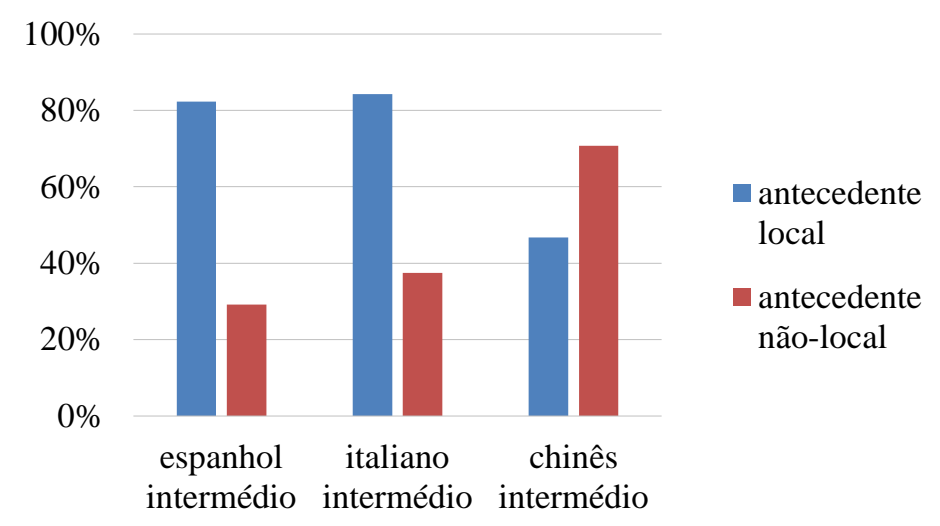

Figura 3. Interpretação do reflexo si em frases complexas - comparação dos resultados dos grupos de falantes nativos de espanhol e italiano com os do grupo de chinês L1 de Fiéis \& Madeira (2016)

Se há transferência da L1 neste domínio, o que poderá então explicar os resultados do grupo de italiano L1? Por um lado, questões metodológicas: em primeiro lugar, estes resultados baseiam-se numa amostra reduzida (12 participantes de nível intermédio e 8 de nível avançado); depois, o contexto que foi testado, em que o pronome reflexo ocorre numa oração completiva de indicativo, é um contexto que, de acordo com Napoli (1979), não permite ligação de longa distância em italiano. Além disso, havendo evidência de variação nos juízos de falantes nativos de italiano no que diz respeito à possibilidade de ligação de longa distância (cf. secção 5.3), a ausência de evidência de um efeito facilitador da L1 no desempenho dos participantes no nosso estudo, falantes nativos de italiano, poderá dever-se à ausência desta opção das suas gramáticas nativas. De qualquer modo, fica por explicar o melhor desempenho do grupo de falantes de espanhol L1, que, como vimos, é uma língua que também não permite ligação de longa distância. Estas são questões que procuraremos explorar em investigação futura.

A hipótese (4) confirma-se no caso do grupo de espanhol L1, já que se observa um efeito de desenvolvimento na passagem do nível intermédio para o nível avançado, apresentando o grupo avançado já um desempenho que não difere significativamente do do grupo de controlo no que se refere à aceitação de antecedentes não locais para a anáfora $s i$ em contextos de ligação de longa distância, o que mostra que este conhecimento pode ser adquirido. A hipótese não se confirma, porém, para o grupo de italiano, que seria o grupo que se esperaria estar em vantagem na aquisição, em PE L2, das propriedades da anáfora si em frases complexas. Esta é também uma questão a explorar futuramente.

Observámos que, em contextos potenciais de longa distância, o grupo de controlos nativos apresenta variação na interpretação de $s i$, não mostrando uma preferência clara nem pelo antecedente local nem pelo não local. Note-se, também, que a aceitação de cada um destes dois antecedentes não é tão elevada como se esperaria, rondando os $60 \%$. Resultados idênticos têm sido observados em falantes nativos de outras línguas que permitem ligação de longa distância (e.g. Thomas, 1991), o que parece confirmar que estas são estruturas que envolvem custos mais elevados de processamento, devido à presença de dois potenciais antecedentes na frase, resultando numa maior variabilidade dos resultados.

Esta poderá também ser a razão por que, embora os falantes não nativos manifestem uma preferência por antecedentes locais para o pronome reflexo si em frases complexas, as taxas de aceitação destes antecedentes são mais baixas do que as verificadas em frases simples (o que corrobora a nossa hipótese (2)). Esta observação encontra confirmação também nos resultados de estudos anteriores, que mostram que a presença na frase de um antecedente alternativo para o pronome reflexo pode influenciar negativamente a aceitação de um antecedente local (e.g. Thomas, 1991). 


\section{Referências}

Brito, Ana Maria (2003) Tipologia e distribuição das expressões nominais: Distribuição das expressões anafóricas. In M.H. Mateus et al. (eds.) Gramática da Língua Portuguesa. Lisboa: Caminho, pp. 801-915.

Chien, Yiu-Chin \& Ken Wexler (1990) Children's knowledge of locality conditions in binding as evidence for the modularity of syntax and pragmatics. Language Acquisition 1 (3), pp. 225-295.

Chomsky, Noam (2000) Minimalist inquires: The framework. In R. Martin, D. Michaels \& J. Uriagereka (eds.) Step by step: Essays on minimalist syntax in honor of Howard Lasnik. Cambridge, MA: MIT Press, pp. 89-155.

Cole, Peter, Gabriella Hermon \& Cher Leng Lee (2001) Grammatical and discourse conditions on long distance reflexives in two Chinese dialects. In Peter Cole, Gabriella Hermon \& C.-T. James Huang (orgs.) Long-Distance Reflexives, Volume 33 (Syntax and Semantics). Nova Iorque: Academic Press, pp. 1-46.

Domínguez, Laura, Glyn Hicks \& Hee-Jeong Song (2012) Untangling Locality and Orientation Constraints in the L2 Acquisition of Anaphoric Binding: A Feature-Based Approach. Language Acquisition 19 (4), pp. 266-300.

Fiéis, Alexandra \& Ana Madeira (2016) Interpretação de pronomes e aquisição de dependências referenciais em português L2. Revista da Associação Portuguesa de Linguística 2, pp. 253-264.

Giorgi, Alessandra (1984) Toward a theory of long-distance anaphora: A GB approach. Linguistic Review 3, pp. 307-359.

Grodzinsky, Yosef \& Tanya Reinhart (1993) The Innateness of Binding and Coreference. Linguistic Inquiry 24 (1), pp. 69-101.

Kim, Eunah, Silvina Montrul \& James Yoon (2014) The on-line processing of binding principles in second language acquisition: evidence from eye tracking. Applied Psycholinguistics 36 (6), pp. 1317-1374.

Manzini, Maria Rita \& Ken Wexler (1987) Parameters, binding theory, and learnability. Linguistic Inquiry 18 (3), pp. 413-444.

Menuzzi, Sergio (1999) Binding Theory and Pronominal Anaphora in Brazilian Portuguese. The Hague: Holland Academin Graphics.

Menuzzi, Sergio \& Maria Lobo (2016) Binding and pronominal forms in Portuguese. In W. L. Wetzels, S. Menuzzi \& J. Costa (eds.) The Handbook of Portuguese Linguistics. Hoboken, NJ: John Wiley \& Sons, Inc, pp. 338-355.

Napoli, Donna Jo (1979) Reflexivization across clause boundaries in Italian. Journal of Linguistics 15, pp. 1-27.

Otero, Carlos (1999) Pronombres reflexivos y recíprocos. In I. Bosque \& V. Demonte (orgs.) Gramática Descriptiva de la Lengua Española. Madrid: Espasa-Calpe, pp. 1428-1517.

Reinhart, Tanya \& Eric Reuland (1993) Reflexivity. Linguistic Inquiry 24 (4), pp. 657-720.

Schwartz, Bonnie \& Rex Sprouse (1996) L2 cognitive states and the full transfer/full access model. Second Language Research 12, pp. 40-72.

Shirahata, Tomohiko (2007) Interpretation of English pronouns and reflexives by Japanese learners. Shizuoka University Department of Education Bulletin 57, pp. 141-156.

Shirahata, Tomohiko, Noriko Yoshimura \& Koichi Sawasaki (2015) Locality and disjointness in adult second language acquisition. In Cornelia Hamann \& Esther Ruigendijk (orgs.) Language Acquisition and Development: Proceedings of GALA 2013. Cambridge Scholars Publications, pp. 460-475.

Silva, Carolina (2015) Interpretation of clitic, strong and null pronouns in the acquisition of European Portuguese. Dissertação de doutoramento, Universidade Nova de Lisboa.

Sorace, Antonella (2011) Pinning down the concept of "interface" in bilingualism. Linguistic Approaches to Bilingualism 1 (1), pp. 1-33. 
Sorace, Antonella \& Francesca Filici (2006) Anaphora resolution in near-native speakers of Italian. Second Language Research 22 (3), pp. 339-368.

Sperlich, Darcy (2013) The acquisition of long-distance reflexives in Chinese as an interlanguage: an experimental study. Dissertação de doutoramento, The University of Auckland.

Thomas, Margaret (1993) Knowledge of Reflexives in a Second Language. Amsterdam/Philadelphia: John Benjamins.

Thomas, Margaret (1991) Universal Grammar and the interpretation of reflexives in a second language. Language 67, pp. 211-239.

Thomas, Margaret (1989) The interpretation of English reflexive pronouns by non-native speakers. Studies in Second Language Acquisition 11, pp. 281-303.

White, Lydia (2003) Second Language Acquisition and Universal Grammar. Cambridge: Cambridge University Press.

White, Lydia, Joyce Bruhn-Garavito, Takako Kawasaki, Joe Pater \& Philippe Prévost (1997) The researcher gave the subject a test about himself: problems of ambiguity and preference in the investigation of reflexive binding. Language Learning 47 (1), pp. 145-172.

Yuan, Boping (1998) Interpretation of binding and orientation of the Chinese reflexive ziji by English and Japanese speakers. Second Language Research 14 (4), pp. 324-340. 